\title{
Polydopamine assisting the continuous growth of zeolitic imidazolate framework-8 on electrospun polyacrylonitrile fibers as efficient adsorbent for improved removal of $\mathrm{Cr}(\mathrm{VI})$
}

Xu Yang

Harbin Institute of Technology

Yuhong Zhou

Harbin Institute of Technology

Zhaojie Sun

Harbin Institute of Technology

Chunhui Yang

Harbin Institute of Technology

Dongyan Tang ( $\nabla$ dytang@hit.edu.cn )

Harbin Institute of Technology https://orcid.org/0000-0002-9641-8609

\section{Research Article}

Keywords: Electrospun fibers, polydopamine, zeolitic imidazolate framework-8, adsorption, $\mathrm{Cr}(\mathrm{VI})$

Posted Date: March 17th, 2021

DOI: https://doi.org/10.21203/rs.3.rs-303320/v1

License: (c) (1) This work is licensed under a Creative Commons Attribution 4.0 International License.

Read Full License 


\section{Abstract}

Polydopamine-functionalized polyacrylonitrile (PAN) fibers and integration zeolitic imidazolate framework-8 (ZIF-8) into electrospun fibers both have been proved the greater potential in removal $\mathrm{Cr}(\mathrm{VI})$ ions from aqueous solution, based on our previous works. Here, an efficiency adsorbent was facilely fabricated by polydipamine (PDA) coating assisting ZIF-8 growth on the electrospun PAN fibers. Benefiting from abundant functional groups (including amino and hydroxyl) of PDA coating, the ZIF-8 nanoparticles rapidly and effectively grew on the fiber surface, and thicker ZIF-8 layer was obtained by prolonging the reaction time. The obtained composite ZIF-8@PDA/PAN fibers retained high surface area $\left(299.9 \mathrm{~m}^{2} \cdot \mathrm{g}^{-1}\right)$ and pore size, and exhibited super-hydrophilicity and high water-stability, which were vital for the $\mathrm{Cr}(\mathrm{VI})$ removal. The composite fiber exhibited significant removal efficiency (more than $90 \%$ at lower initial $\mathrm{Cr}(\mathrm{VI})$ concentrations), good adsorption capacity $\left(212.7 \mathrm{mg} \cdot \mathrm{g}^{-1}\right)$ and excellent recyclability.

\section{Introduction}

As one of typical metal-organic frameworks (MOFs), zeolitic imidazolate framework-8 (ZIF-8) with high surface area, rich functional groups, tunable physiochemical properties and excellent stability, was considered as effective adsorbent in wastewater treatment (Li et al. 2018; Zhou et al. 2020). However, ZIF8 is usually crystalline powder and disperse in water with the form of small particles, which limit its recovery and reuse in water treatment. Therefore, it is necessary to develop suitable substrates to effectively load ZIF-8 and prepare stable composite materials (Lei et al. 2018; Xie et al. 2020). Moreover, the electrospun fibers, owing to the three-dimensional interwoven structures, can provide active sites for the ZIF-8 loading, and are regarded as one of the ideal substrates for ZIF-8 loading.

In our previous works, using ZIF-8 nanoparticles as crystal seeds, stable ZIF-8@ZIF-8/PAN fibers were successfully fabricated by combining electrospinning with multiple in-situ growth, and the obtained composite fibers showed good adsorbent capacity for $\mathrm{Cr}(\mathrm{VI})$ (Ramezani et al. 2019). Herein, for further exploring a simpler strategy to fabricate MOFs-based fibers and enhancing its adsorption ability, polydopamine (PDA) with peculiar and abundant functional groups was selected for assisting the continuous growth of ZIF-8 on electrospun PAN fiber (as shown in Scheme 1). The formed PDA coatings were beneficial to improve the affinity to metal ions by introducing abundant functional groups (including amino and hydroxyl), accelerating the generation and order distribution of ZIF-8 particles on fibers' surface, and further improving the adsorption ability of the complex materials toward $\mathrm{Cr}(\mathrm{VI})$ ions (Yang et al. 2020a). Then the morphology, structures and adsorption abilities to hexavalent chromium $(\mathrm{Cr}(\mathrm{VI}))$ of the composite fibers were investigated.

\section{Material And Methods}

\subsection{Materials}


The details of chemicals used in this work, and the material detection method of morphology and structure were illustrated in Supplementary Information.

\subsection{Preparation of ZIF-8@PDA/PAN fiber}

PAN/PDA composite fibers was fabricated according to our previous work (Yang et al. 2020b). For the preparation of ZIF-8@PDA/PAN, $0.2974 \mathrm{~g}$ of $\mathrm{Zn}\left(\mathrm{NO}_{3}\right)_{2} \cdot 6 \mathrm{H}_{2} \mathrm{O}$ was dissolved in $20 \mathrm{~mL}$ of methanol (solution a), and $0,6568 \mathrm{~g}$ of 2-methylimidazole was dissolved in $10 \mathrm{~mL}$ of methanol (solution b). Then, PAN/PDA fibers were immersed into solution a for $30 \mathrm{~min}$, following the mixing with solution $b$ and standing for a period of time (from 0 to $40 \mathrm{~min}$ ) at room temperature. Finally, the obtained composite fibers were washed with methanol for three times and dried under vacuum at $60^{\circ} \mathrm{C}$ overnight. The preparation of ZIF-8@PAN fiber was similar to ZIF-8@PDA/PAN. Then, $\mathrm{Cr}(\mathrm{VI})$ was chosen as targeted heavy metal pollutant to investigate the adsorption behaviors, the details of $\mathrm{Cr}(\mathrm{VI})$ removal experiments and adsorption detection were shown in Supplementary Information.

\section{Result And Discussion}

\subsection{Morphology and Structural Characterization of ZIF-8@PDA/PAN fibers}

To investigate the coating process of ZIF-8 particles on fibers surface, the morphologies of ZIF8@PDA/PAN fibers with different time-course were affirmed by the corresponding SEM images (as shown in Fig. 1a-h). When PAN/PDA fibers were soaked into zinc ions and imidazole mixed solution for 5 min, there were few ZIF-8 particles scattering sparsely and randomly on the surface of the fibers. Further increasing the reaction time, more and more ZIF-8 particles generated obviously on the surfaces. When the reaction time up to $20 \mathrm{~min}$, a uniform and compact ZIF-8 layer was formed on the surface, which promoted accumulation of ZIF-8 particles. Although the composite fiber surface was covered completely by ZIF-8 particles, the fibrous structures was remained perfectly with the increased surface roughness. Remarkably, with further prolonging the reaction time, the fibers coated with thicker and dense ZIF-8 layer. Accompanying with the growth process and layer formation process of ZIF-8. the average diameter (A. D.) of fibers increased from 0.79 to $1.55 \mu \mathrm{m}$. In short, owing to the thick ZIF-8 coating and uniform diameter distributions, the composite fiber with growth time of $40 \mathrm{~min}$ was selected as the sample for the following detection and adsorption experiment.

Besides, the morphology of PAN fibers with the loaded ZIF-8 particles was also shown in Figure S1, there were much less nanoparticles on the surface than PAN/PDA fibers, indicating the lower loading abilities and the poor continuity of ZIF-8 nanoparticles onto PAN fibers. Therefore, the modification of substrate or loading way might be of great significant to further improve its affinity of fibers and guarantee the plenty of ZIF-8 growing on PAN fiber surface. Moreover, to verify the probable interfacial interactions between PDA coatings and loaded ZIF-8 nanoparticles, XPS analysis was further conducted. As shown in Fig. 1i-j, the obvious peak of $\mathrm{Zn} 2 \mathrm{p}$ confirmed the anchoring of ZIF-8 on fibers, and the peak at $531.8 \mathrm{eV}$ for $01 \mathrm{~s}$ was attributed to Zn-O-H (Zhu et al. 2017), indicating that the attachment of ZIF-8 was driven by the covalent boding between oxygen groups of PDA and Zn centers. These analyses affirmed the fibrous 
morphology and the PDA coatings on PAN fibers, which were both the beneficial factors for the continuous growth and the uniformed distributions of ZIF-8 nanoparticles onto fibers surface.

The FI-IR and XRD analysis were further conducted to verify the structures and the components of the fabricated fibers (Figure S2). The several obvious peaks of ZIF-8@PDA/PAN at 7.2 $2^{\circ}, 10.4^{\circ}, 12.7^{\circ}$ and $18.0^{\circ}$ were corresponded to (001), (002), (112) and (222), respectively (Venna et al. 2010). These peaks both matched well with ZIF-8 crystals and the simulated data, indicating the in-situ growth of ZIF-8 nanoparticles onto the fibers and the highly remaining crystallinity. Then, seen from FT-IR spectra, the peak at $2240 \mathrm{~cm}^{-1}$ was assigned to the stretching vibration of $-\mathrm{CN}$ within polyacrylonitrile structure (Zhang et al. 2010). The peaks at $3460,1231 \mathrm{~cm}^{-1}$ were ascribed to the stretching vibration of $-\mathrm{NH}, \mathrm{C}-\mathrm{O}$ within aromatic benzene structure of polydopamine, respectively (Ma et al. 2017). While the peaks at 3136,1144 and $1564 \mathrm{~cm}^{-1}$ were attributed to the stretching vibration of $\mathrm{C}-\mathrm{H}, \mathrm{C}-\mathrm{N}$ and the bending vibration of $\mathrm{C}=\mathrm{N}$ within the structure of methylimidazole ring of ZIF-8, respectively (Karimi et al. 2019). All the above observed peaks were also co-existent in the spectra of the composite fibers, confirming the successful anchoring of ZIF-8 nanoparticles onto the surface of PAN fibers.

Furthermore, $\mathrm{N}_{2}$ adsorption analysis was further conducted to verify the composite fiber high surface area and orderly pore-size distribution. As shown in Figure S3, the adsorption-desorption isotherms the composite fibers were classic type-I with a sharp increase within low-pressure $\left(P / P_{0}<0.1\right)$, confirming its microporous characteristics. Besides, the existence of a hysteresis loop for the isotherm of ZIF-8 was due to the accumulation of ZIF-8 nanoparticles and the generation of the mesopores. While there was no hysteresis loop for the composite fibers, demonstrating the uniformly growth of ZIF-8 onto the fibers, and the perfect solutions of the accumulation issue of ZIF-8 nanoparticles. The corresponding pore-size distributions were calculated by Horvath-Kawazoe equation. The composite fibers exhibited the ranges of the main pore sizes from 0.6 to $0.8 \mathrm{~nm}$, larger than that the radii of chromium ions $(0.4 \mathrm{~nm})$ (Ding et al. 2017) and thus it was beneficial for the adsorption to $\mathrm{Cr}(\mathrm{VI})$. Furthermore, based on Beunauer-EmmettTeller (BET) equation, the calculated surface area and pore volume of the composite fiber were 299.9 $\mathrm{m}^{2} \cdot \mathrm{g}^{-1}$ and $0.1657 \mathrm{~cm}^{3} \cdot \mathrm{g}^{-1}$, respectively. The higher BET surface area and large pore volume were caused by the loading of ZIF-8, which could enhance the adsorption performance of the composite fibers.

Usually, for the membrane materials with wide application in wastewater treatment, a hydrophilic surface was one of the key factor to meet the requirement (Kim et al. 2017). Here, we measured the static contact angles of ultra-pure water on the fibrous membrane to evaluate its hydrophilicity (as shown in Fig. 1k-n). The contact angles of thin ZIF-8 piece was stable at about $53.59^{\circ}$ within the contact period of 10 seconds, indicating that it was hydrophilics. While the composite fibers adsorbed the water droplets immediately and the contact angles was $0^{\circ}$ within one second, verifying its super-hydrophilicities. Moreover, after the contact with angle, the composite fibers preserved its original forms. Hence, the composite fibers that possessed super hydrophilicity and water stability would further afford the fibers great probability to apply in the field of water treatment.

\subsection{The adsorption behavior and the removal capacity of $\mathrm{Cr}(\mathrm{VI})$}

Page $4 / 11$ 
Figure 2 (a) UV-visible spectra of DPC-Cr(VI) complex solutions after being adsorbed by the ZIF8@PDA/PAN fibers with increasing time. (b) The comparison of $\mathrm{Cr}(\mathrm{VI})$ adsorption capacity by the composite fibers and ZIF-8 particles with increasing time. (c) The digital photographs exhibited the $\mathrm{Cr}(\mathrm{VI})$ solution of various concentrations before and after adsorbing by the composite fibers. The comparison of (d) removal efficiency and (e) adsorption capacity by the composite fibers and ZIF-8 particles toward $\mathrm{Cr}(\mathrm{VI})$ with increasing initial concentrations.

The adsorption ability of ZIF-8@PDA/PAN fibers was investigated by using $\mathrm{Cr}(\mathrm{VI})$ as the probe adsorbate. In Fig. 2a, there was an obvious absorption peak at $540 \mathrm{~nm}$, which was used to describe the adsorption process of $\mathrm{Cr}(\mathrm{VI})$ by the composite fibers. The intensity of the absorption peak decreased with the increasing time, and it almost disappeared after 90 min adsorption time, indicating the decreasing of $\mathrm{Cr}(\mathrm{VI})$ concentration within the solution and an efficient adsorbent of the composite fibers. Then the comparison of $\mathrm{Cr}(\mathrm{VI})$ adsorption capacity between the composite fibers and ZIF-8 particles were shown in Fig. 2b, with ZIF-8 as adsorbent, the absorption equilibrium of $\mathrm{Cr}(\mathrm{VI})$ was achieved after 60 minutes, and ZIF-8 exhibited relative lower adsorption ability with the equilibrium adsorption capacity $\left(q_{e}\right)$ of 21.8 $\mathrm{mg} \cdot \mathrm{g}^{-1}$. Under the same conditions, $\mathrm{Cr}(\mathrm{VI})$ absorption reached to the equilibrium state after $100 \mathrm{~min}$ when the composite fiber was used as adsorbent, and the $q_{e}$ was calculated to be $101.6 \mathrm{mg} \cdot \mathrm{g}^{-1}$, which was almost 5 times large than single ZIF-8. Therefore, utilizing PDA as an adhesion coating to effectively anchor ZIF-8 onto the fibers was obvious beneficial to the improvement of adsorption capacity of the composite.

Figure 2c presented serial digital photographs before and after the adsorbing of $\mathrm{Cr}(\mathrm{VI})$ solution with various concentrations by the composite fibers. The initial concentrations of $\mathrm{Cr}(\mathrm{VI})$ were $20 \mathrm{mg} \cdot \mathrm{L}^{-1}$ and $1.0 \mathrm{~g} \cdot \mathrm{L}^{-1}$ to the composite fibers, the color of $\mathrm{Cr}(\mathrm{VI})$ solution changed from orange to transparent after 90 min's adsorption. Under the same conditions, there was also obvious color change for serial $\mathrm{Cr}(\mathrm{VI})$ solution that with higher initial concentrations. Besides, the composite fibers had a significant removal efficiency of more than 90 percent with the initial concentrations below $100 \mathrm{mg} \cdot \mathrm{L}^{-1}$ (as shown in Fig. 2d), and it also showed comparable or superior adsorption ability with $212.7 \mathrm{mg} \cdot \mathrm{g}^{-1}$ to other reported adsorbents (as shown in Table 1). In addition, the potential recycled utilization of the composite fibers for $\mathrm{Cr}(\mathrm{VI})$ removal was further estimated and illustrated in Figure S4. After five adsorption cycles, the adsorption amount of the composite fibers towards $\mathrm{Cr}(\mathrm{VI})$ was about $75 \mathrm{mg} \cdot \mathrm{g}^{-1}$, which was about $75 \%$ of the first adsorption, indicating the good recyclability of composite fibers. 
Table 1

The comparison of the adsorption capacity of $\mathrm{Cr}(\mathrm{VI})$ by different adsorbents.

\begin{tabular}{|llll|}
\hline Adsorbent & $\begin{array}{l}\text { Adsorption capacity } \\
\left(\mathbf{m g} \cdot \mathbf{g}^{-1}\right)\end{array}$ & $\begin{array}{l}\text { Kinetics } \\
(\mathbf{m i n})\end{array}$ & References \\
\hline Polyacrylonitrile/polydopamine fiber & 61.6 & 480 & Yang et al. 2020b \\
\hline magnetite-boehmite sol-gel & 62.4 & 60 & $\begin{array}{l}\text { Shapovalova } \\
\text { et al. 2020 }\end{array}$ \\
\hline $\begin{array}{l}\text { EDTA complexed Acacia auriculiformis } \\
\text { biomass }\end{array}$ & 145.7 & 240 & $\begin{array}{l}\text { Shahnaz et al. } \\
\text { 2020 }\end{array}$ \\
\hline Polydopamine microsphere & 200.2 & 8 & Zhang et al. 2018 \\
\hline $\begin{array}{l}\text { Chitosan and hydrogen peroxide-treated } \\
\text { anthracite sheets }\end{array}$ & 201.7 & 120 & $\begin{array}{l}\text { Mohamed et al. } \\
\text { 2020 }\end{array}$ \\
\hline Fe $\mathrm{S}_{4}$ micro-crystal & 231.3 & 100 & Yang et al. 2020c \\
\hline Magnetic core-shell MoS ${ }_{2} @ F_{3} \mathrm{O}_{4}$ & 290.2 & 90 & Yang et al. 2020d \\
\hline ZIF-8@PDA/PAN fibers & 212.7 & 90 & This work \\
\hline
\end{tabular}

\section{Conclusions}

In summary, the efficiency adsorbent based on electrospun fibers and ZIF-8 nanoparticles was facilely fabricated by surface modifying with PDA, which provided functional groups to induce the interaction between fiber surface and ZIF-8 nanoparticles. The obtained ZIF-8@PDA/PAN fibers maintained typical and stable fibrous morphology with uniform and orderly nanoparticles on the entire fibrous surfaces. The composite fibers owned higher surface areas and appropriate pore size, and also showed superhydrophilicity and excellent water-stability. Especially, the composite fibers exhibited significant removal efficiency (more than 90\%) at relative lower initial $\mathrm{Cr}(\mathrm{VI})$ concentrations, and also showed high adsorption capacity toward $\mathrm{Cr}(\mathrm{VI})\left(212.7 \mathrm{mg} \cdot \mathrm{g}^{-1}\right)$ with excellent recyclability. Therefore, the facile synthesis strategy of polydopamine-assisted continuous growth of ZIF-8 on electrospun fibers was available to fabricate MOF-based composites and could show great potential in adsorption of metal ions.

\section{References}

Li J, Wang X, Zhao G, Chen C, Chai Z, Alsaedi A, Hayat T, X. Wang X (2018) Metal-organic frameworkbased materials: superior adsorbents for the capture of toxic and radioactive metal ions. Chem Soc Rev 47:2322-2356.

Zhou L, Li N, Jin X, Owens G, Chen Z (2020) A new nFe@ZIF-8 for the removal of Pb(II) from wastewater by selective adsorption and reduction. J Colloid Interf Sci 565:167-176. 
Lei Z, Deng Y, Wang C (2018) Multiphase surface growth of hydrophobic ZIF-8 on melamine sponge for excellent oil/water separation and effective catalysis in a Knoevenagel reaction. J Mater Chem A 6:32583263.

Xie A, Cui J, Yang J, Chen Y, Lang J, Li C, Yan Y, Dai J (2020) Dual superlyophobic zeolitic imidazolate framework-8 modified membrane for controllable oil/water emulsion separation. Sep Purif Technol 236.

Ramezani MR, Ansari-Asl Z, Hoveizi E, Kiasat AR (2019) Polyacrylonitrile/Fe(III) metal-organic framework fibrous nanocomposites designed for tissue engineering applications. Mater Chem Phys 229:242-250.

Yang X, Zhou Y, Sun Z, Yang C, Tang D (2020) Effective strategy to fabricate ZIF-8@ZIF-8/polyacrylonitrile nanofibers with high loading efficiency and improved removing of $\mathrm{Cr}(\mathrm{VI})$. Colloid Surface $\mathrm{A} 603$.

Yang X, Zhou Y, Sun Z, Yang C, Tang D (2020) Synthesis and Cr adsorption of a super-hydrophilic polydopamine-functionalized electrospun polyacrylonitrile. Environ Chem Lett 19:743-749

Zhu K, Chen C, Xu H, Gao Y, Tan X, Alsaedi A, Hayat T (2017) Cr(VI) Reduction and Immobilization by Core-Double-Shell Structured Magnetic Polydopamine@Zeolitic Idazolate Frameworks-8 Microspheres. ACS Sustain Chem Eng 5:6795-6802.

Venna SR, Jasinski JB, Carreon MA (2010) Structural Evolution of Zeolitic Imidazolate Framework-8. J Am Chem Soc 132:18030-18033.

Zhang D, Karki AB, Rutman D, Young DR, Wang A, Cocke D, Ho TH, Guo Z (2009) Electrospun polyacrylonitrile nanocomposite fibers reinforced with $\mathrm{Fe}_{3} \mathrm{O}_{4}$ nanoparticles: Fabrication and property analysis. Polymer 50:4189-4198.

Ma FF, Zhang N, Wei X, Yang JH, Wang Y, Zhou ZW (2017) Blend-electrospun poly(vinylidene fluoride)/polydopamine membranes: self-polymerization of dopamine and the excellent adsorption/separation abilities. J Mater Chem A 5:14430-14443.

Karimi A, Vatanpour V, Khataee A, Safarpour M (2019) Contra-diffusion synthesis of ZIF-8 layer on polyvinylidene fluoride ultrafiltration membranes for improved water purification. J Ind Eng Chem 73:95105.

Ding Y, Xu Y, Ding B, Li Z, Xie F, Zhang F, Wang H, Liu J, Wang X (2017) Structure induced selective adsorption performance of ZIF-8 nanocrystals in water. Colloid Surface A 520:661-667.

Kim D, KimV DW, Buyukcakir O, Kim MK, Polychronopoulou K, Coskun A (2017) Highly hydrophobic ZIF$8 /$ carbon nitride foam with hierarchical porosity for oil capture and chemical fixation of $\mathrm{CO}_{2}$. Adv Funct Mater 27.

Shapovalova OE, Drozdov AS, Bryushkova EA, Morozov MI, Vinogradov VV (2020) Room-temperature fabrication of magnetite-boehmite sol-gel composites for heavy metal ions removal. Arab J Chem 
Shahnaz T, Patra C, VSharma V, Selvaraju N (2020) A comparative study of raw, acid-modified and EDTAcomplexed Acacia auriculiformis biomass for the removal of hexavalent chromium. Chem Ecol 36:360381.

Zhang Q, Li Y, Yang Q, Chen H, Chen X, Jiao T, Peng Q (2018) Distinguished Cr(VI) capture with rapid and superior capability using polydopamine microsphere: Behavior and mechanism. J Hazard Mater 342:732740 .

Mohamed EA, Selim AQ, Ahmed SA, Sellaoui L, Bonilla-Petriciolet A, Erto A, Li Z, Li Y, Seliem MK (2020) $\mathrm{H}_{2} \mathrm{O}_{2}$-activated anthracite impregnated with chitosan as a novel composite for $\mathrm{Cr}(\mathrm{VI})$ and methyl orange adsorption in single-compound and binary systems: Modeling and mechanism interpretation. Chem Eng J 380 .

Yang S, Li Q, Chen L, Chen Z, Hu B, Wang H, Wang X (2020) Synergistic removal and reduction of U(VI) and $\mathrm{Cr}(\mathrm{VI})$ by $\mathrm{Fe}_{3} \mathrm{~S}_{4}$ micro-crystal. Chem Eng J 385.

Yang S, Li Q, Chen L, Chen Z, Pu Z, Wang H, Yu S, Hu B, Chen J, Wang X (2019) Ultrahigh sorption and reduction of $\mathrm{Cr}(\mathrm{VI})$ by two novel core-shell composites combined with $\mathrm{Fe}_{3} \mathrm{O}_{4}$ and $\mathrm{MoS}_{2}$. $\mathrm{J}$ Hazard Mater 379.

\section{Figures}




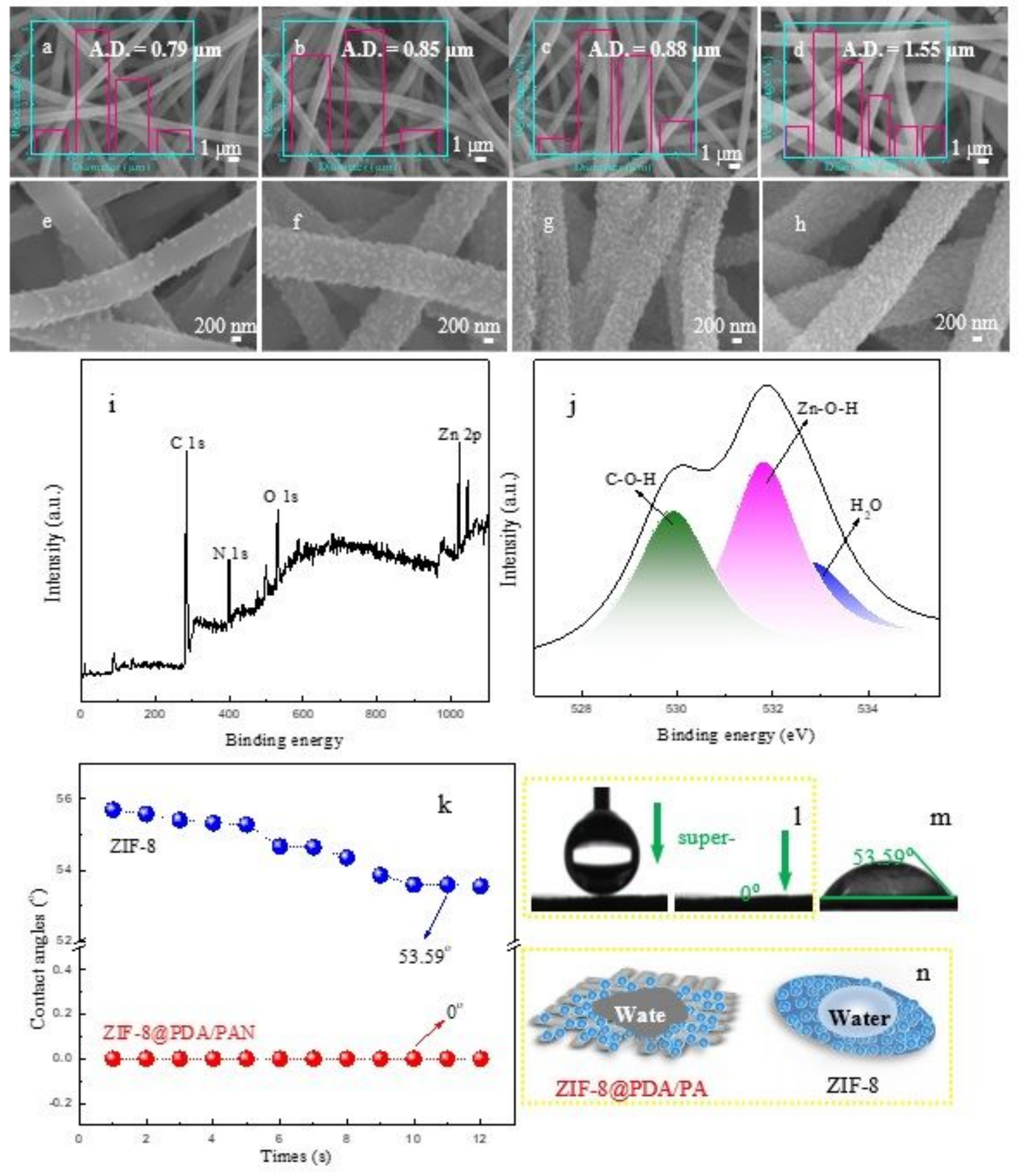

Figure 1

SEM images and the diameter distribution of the ZIF-8@PDA/PAN fibers with ZIF-8 growth time at (a and e) $5 \mathrm{~min}$, (b and f) $10 \mathrm{~min}$, (c and g) $20 \mathrm{~min}$, (d and h) $40 \mathrm{~min}$, respectively. XPS spectra of ZIF8@PDA/PAN: (i) wide scan, (j) high-resolution spectra of 0 1s. ( $\mathrm{k}$ ) Comparison of the contact angle of ultra-pure water on the surfaces of ZIF-8@PDA/PAN fibers and thin ZIF-8 piece. Digital images of contact angle measurements and static contact angle of (I) ZIF-8@PDA/PAN fibers and (m) thin ZIF-8 piece. (n) Schematic description of the hydrophilcity of the different surface. 

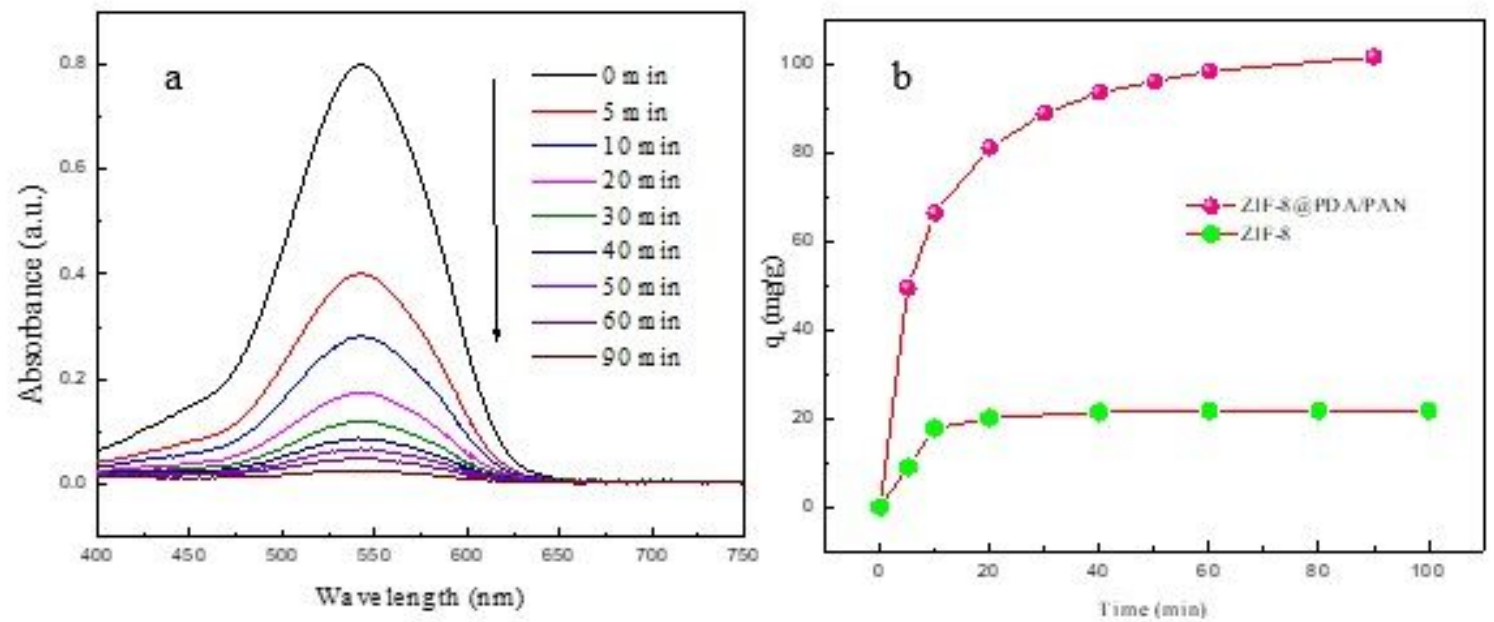

c $\quad 20 \mathrm{mg} / \mathrm{L} \quad 40 \mathrm{mg} / \mathrm{L} \quad 60 \mathrm{mg} / \mathrm{L} \quad 80 \mathrm{mg} / \mathrm{L} \quad 100 \mathrm{mg} / \mathrm{L} \quad 150 \mathrm{mg} / \mathrm{L} \quad 200 \mathrm{mg} / \mathrm{L} \quad 250 \mathrm{mg} / \mathrm{L}$
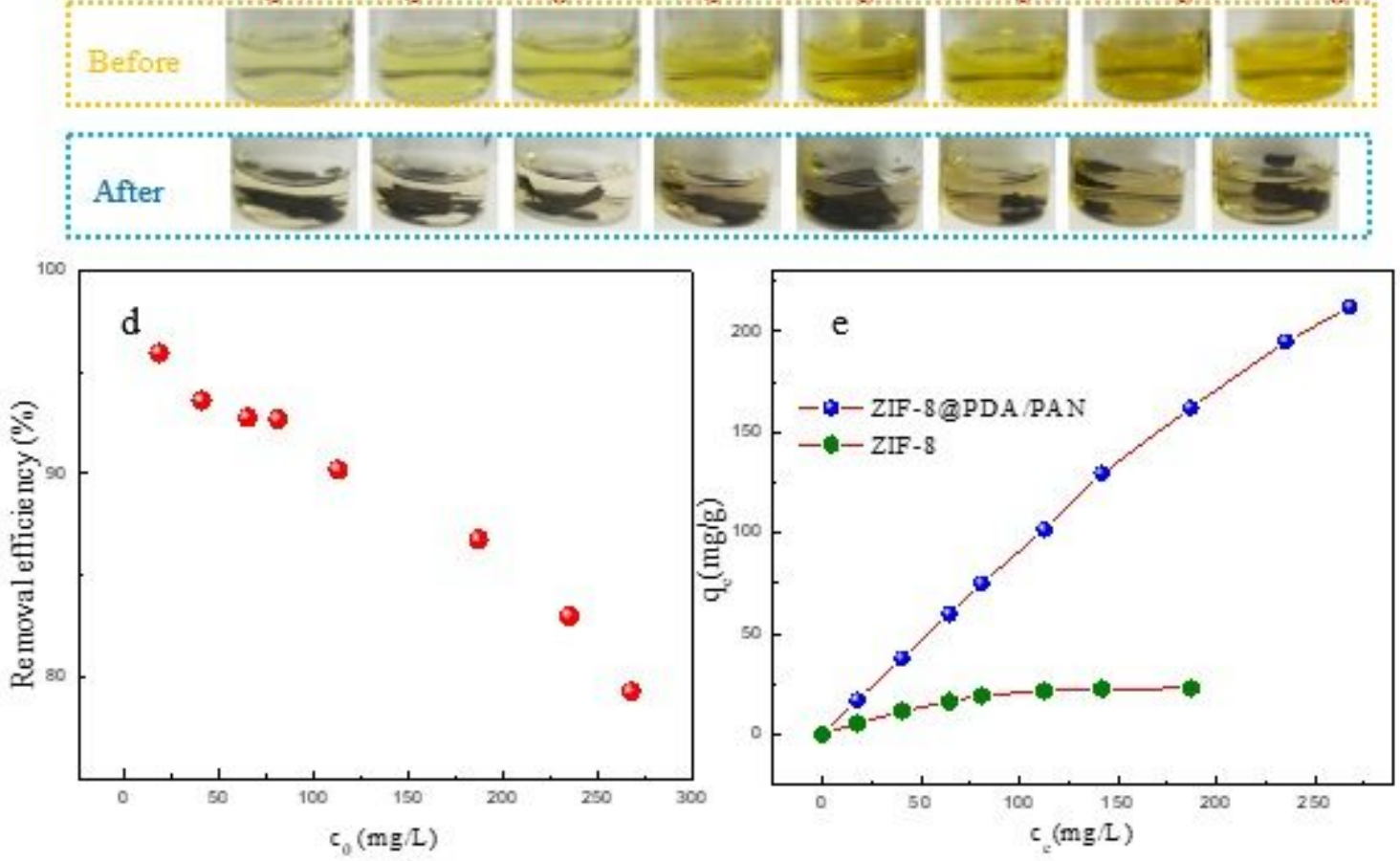

Figure 2

(a) UV-visible spectra of DPC-Cr(VI) complex solutions after being adsorbed by the ZIF-8@PDA/PAN fibers with increasing time. (b) The comparison of $\mathrm{Cr}(\mathrm{VI})$ adsorption capacity by the composite fibers and ZIF-8 particles with increasing time. (c) The digital photographs exhibited the $\mathrm{Cr}(\mathrm{VI})$ solution of various concentrations before and after adsorbing by the composite fibers. The comparison of (d) removal efficiency and (e) adsorption capacity by the composite fibers and ZIF-8 particles toward $\mathrm{Cr}(\mathrm{VI})$ with increasing initial concentrations.

\section{Supplementary Files}

This is a list of supplementary files associated with this preprint. Click to download. 
- Scheme1.pdf

- SupplementaryInformation.docx 